\title{
Activation of endoplasmic reticulum stress and the extrinsic apoptotic pathway in human lung cancer cells by the new synthetic flavonoid, LZ-205
}

\author{
Yi Zhang ${ }^{1, *}$, Xuefen Xu ${ }^{1, *}$, Wei Li ${ }^{1}$, Hanchi Miao ${ }^{1}$, Shaoliang Huang ${ }^{1}$, Yuxin Zhou ${ }^{1}$, \\ Yang Sun ${ }^{1}$, Zhiyu Li' ${ }^{2}$, Qinglong Guo ${ }^{1}$, Li Zhao' \\ ${ }^{1}$ State Key Laboratory of Natural Medicines, Jiangsu Key Laboratory of Carcinogenesis and Intervention, China Pharmaceutical \\ University, Nanjing 210009, People's Republic of China \\ ${ }^{2}$ School of Pharmacy, China Pharmaceutical University, Nanjing 210009, People's Republic of China \\ *These authors have contributed equally to this work \\ Correspondence to: Qinglong Guo, email: anticancer_drug@163.com \\ Li Zhao, email: zhaoli@cpu.edu.cn \\ Keywords: LZ-205, apoptosis, ER stress, ROS, extrinsic apoptosis
}

Received: March 17, $2016 \quad$ Accepted: November 02, $2016 \quad$ Published: November 24, 2016

\section{ABSTRACT}

It has been shown that flavonoids have anti-tumor activity. In this study, LZ205, a newly synthesized flavonoid, was found to be effective in inducing apoptosis in human lung cancer cells in vivo and in vitro. Mechanistically, LZ-205 triggers reactive oxygen species (ROS)-induced endoplasmic reticulum (ER) stress and unfolded protein response, which could be reversed by silencing CHOP, a mediator of the ER stress-associated apoptosis. In addition, LZ-205-induced apoptosis is accompanied by the activation of both the mitochondrial apoptotic and extrinsic pathways, followed by decreased mitochondrial membrane potential $(\Delta \Psi \mathrm{m})$ and the alteration of the expression of mitochondria-related pro- and anti-apoptotic proteins. LZ-205 exhibits a potential antitumor effect in BALB/c nude mice bearing $\mathrm{H} 460$ tumor with low systemic toxicity. In summary, both the ROS-mediated ER stress pathway and the exogenous apoptotic pathway are involved in LZ-205-induced apoptosis in vitro and in vivo. Our data show a therapeutic potential of LZ-205 for the treatment of lung cancer.

\section{INTRODUCTION}

Lung cancer is a major refractory disease which represents a serious threat to human health. Lung cancer is the number one cancer killer among both men and women in the world. Despite the recent findings on the molecular mechanism of lung cancer and the development of novel therapeutic drugs for its treatment, the 5-year survival rate for lung cancer patients has not changed substantially and remains dismal [1]. As the first-line treatment in lung cancer, chemotherapy helps at the expense of severe and debilitating side effects, but provides only modest survival benefit. Therefore, it is imperative to find novel targeted agents against lung cancer.

Apoptosis is well-known as a process of regulated cell death, which plays a major role not only in cell damage or stress, but also in normal development and morphogenesis [2]. This process results in DNA damage and is activated through two distinct pathways, namely the intrinsic or mitochondrial pathway and the extrinsic pathway [3].

The intrinsic pathway depends on various cell stress signals which usually lead to an imbalance of the Bcl-2 family of proteins in favor of apoptosis, mitochondria permeabilization with concomitant release of cytochrome c (Cyt-c) and eventual activation of caspase 9 [4]. Reactive oxygen species (ROS), such as superoxide $\left(\cdot \mathrm{O}_{2}^{-}\right)$, hydrogen peroxide $\left(\mathrm{H}_{2} \mathrm{O}_{2}\right)$, and hydroxyl radicals $(\cdot \mathrm{OH})$, are mainly produced in the mitochondria and lead to oxidative damage [5]. It has been established that the endoplasmic reticulum (ER) is rather sensitive to oxidative stress damage and regulates the oxidative stressinduced cell death $[6,7]$. Interfering with ER function, a condition termed "ER-stress", leads to the accumulation of unfolded and misfolded proteins in the ER and activates the unfolded protein response (UPR), which can help cells adapt to harmful stimuli under physiological conditions. The UPR involves three well-established signaling 
receptors/proteins, namely the inositol-requiring protein$1 \alpha(\operatorname{IRE} 1 \alpha)$, the protein kinase RNA (PKR)-like ER kinase (PERK), and the activating transcription factor 6 (ATF6) [8]. These three receptors bind to the ER resident chaperone binding immunoglobulin protein (Bip/Grp78), which keeps them inactive. When too much misfolded or unfolded proteins accumulate, the ER releases the Bip protein from these complexes to assist with the folding of the accumulated proteins. The UPR reduces the accumulation of unfolded proteins and restores ER function to promote cell viability in adverse environments. However, when the stress condition remains unresolved, the UPR becomes a pro-apoptotic response [9].

Apoptosis is activated via the extrinsic or death receptor-mediated pathway when a specific ligand binds to its corresponding death receptor in the cell surface. Stimulation of death receptors, such as Fas and Trail, leads to the recruitment of the adaptor molecule Fas-associated death domain (FADD), which in turn recruits procaspase- 8 to the receptor complex and eventually activates the apoptotic signaling cascade $[10,11]$.
Natural flavonoids comprise a group of compounds widely found in plant sources. They have been extensively recognized to have anti-inflammatory, antioxidant, antiallergic, hepatoprotective, antithrombotic, and antiviral activities [12]. The most significant finding in flavonoids research in the last ten years is that flavonoids have antitumor activity [13]. Wogonin is one of the major compounds found in Scutellaria baicalensis and possesses potent anticancer activity. In order to improve its water solubility and druggability, LZ-205, 5-hydroxy-8-methoxy-7-(4(pyrrolidin-1-yl)-butoxy)-2- (4-(trifluoromethyl)-phenyl)4H-chromen-4-one), was synthesized. The synthetic route to LZ-205 is depicted in Figure 1A. Initially, the Friedel-Crafts acylation reaction between 2, 5-dimethoxy-benzene-1, 3-diol (1) and 3-(4-(trifluoromethyl) phenyl) acryloyl chloride yielded chalcone (2) which was then cyclized by iodine oxidation. The phenolic hydroxyl group at the $\mathrm{C} 7$ position of intermediate 3 was then alkylated using 1, 4-dibromobutane in acetone in the presence of $\mathrm{K}_{2} \mathrm{CO}_{3}$. After the selective demethylation, pyrrolidine groups were coupled with the halogenated hydrocarbons to produce LZ-205.
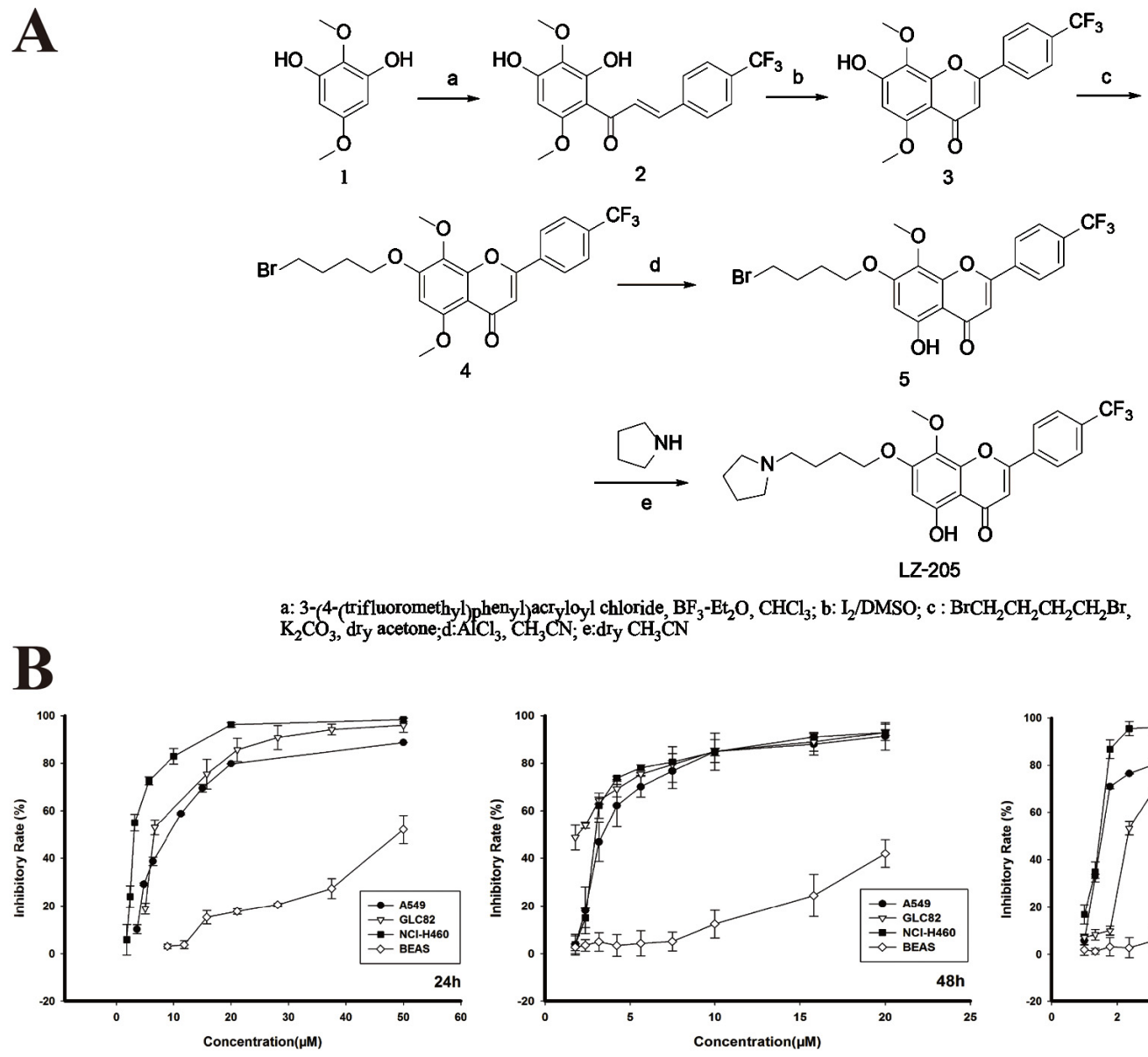

a: 3-(4-(trifluoromethyl)phenyl)acryloyl chloride, $\mathrm{BF}_{3}-\mathrm{Et}_{2} \mathrm{O}, \mathrm{CHCl}_{3} ; \mathrm{b}: \mathrm{I}_{2} / \mathrm{DMSO} ; \mathrm{c}: \mathrm{BrCH}_{2} \mathrm{CH}_{2} \mathrm{CH}_{2} \mathrm{CH}_{2} \mathrm{Br}$,
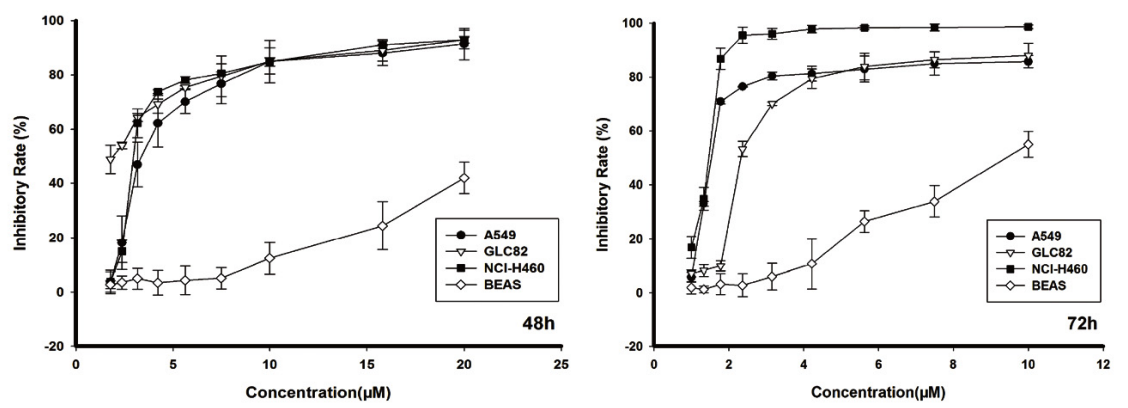

Figure 1: Growth inhibitory effect of LZ-205 in vitro. A. The synthetic route of LZ-205. The molecular structure of LZ-205 $\left(\mathrm{C}_{25} \mathrm{H}_{26} \mathrm{~F}_{3} \mathrm{NO}_{5}, \mathrm{MW}=477.47\right)$, Structure (1) is 2, 5-Dimethoxy-benzene-1, 3-diol $\left(\mathrm{C}_{8} \mathrm{H}_{10} \mathrm{O}_{4}, \mathrm{MW}=170.16\right)$. B. A549, GLC82, NCI-H460 and BEAS cells were treated with various concentration of LZ-205 for 24, 48 and $72 \mathrm{~h}$. Cell viability was determined using MTT assay. Data were shown as Means $\pm \operatorname{SD}(n=3)$. 
Considering the aforementioned factors, in this study we shed some light on the apoptosis-inducing effect of LZ-205 on human lung cancer cells and nude mice H460 xenograft. Our findings also revealed the molecular mechanisms whereby LZ-205 induces apoptosis in vitro and in vivo.

\section{RESULTS}

\section{LZ-205 selectively inhibits human lung cancer cells but not normal cells}

To evaluate cell viability in vitro, the MTT assay was used to determine the cell growth inhibitory effect of LZ205 on human lung cancer cells. The $\mathrm{IC}_{50}$ values of $\mathrm{A} 549$, GLC82 and NCI-H460 cells at $24 \mathrm{~h}$ were $8.37 \pm 0.17$, $7.60 \pm 0.74$ and $3.93 \pm 0.32 \mu \mathrm{M}$, respectively, as shown in Figure 1B. In addition, LZ-205 inhibited the growth of NCI-H460 cells in a time- and concentration- dependent manner, as indicated by the $\mathrm{IC}_{50}$ values measured at 48 and $72 \mathrm{~h}$, which were $2.51 \pm 0.18$ and $1.31 \pm 0.09 \mu \mathrm{M}$, respectively. However, only a small percentage of cell death occurred in normal lung epithelial BEAS cells after treatment with the same concentration of LZ-205. These data suggested that LZ-205 had a selectively inhibitory effect on lung cancer cells but not on normal cells.

\section{LZ-205 induces apoptosis in human lung cancer cells}

Whether the anti-tumor activity of LZ-205 could be due to its apoptosis-inducing effect was investigated. We first examined the morphological changes in NCI-H460 cells treated with 4,6 , or $8 \mu \mathrm{M}$ of LZ-205 or $120 \mu \mathrm{M}$ of Wogonin for $24 \mathrm{~h}$. Observation of the treated cells revealed that they were round and shrunken, indicating that they were apoptotic, whereas the untreated cells retained their normal size and shape, as shown in Figure 2A.

In order to confirm the occurrence of apoptosis, further morphological changes were evaluated by DAPI staining. The LZ-205-treated cells showed bright fluorescent staining, major characteristics of chromatin agglutination, nucleolus pyknosis, and apoptosis (white arrow), as shown in Figure 2B. With the increasing concentrations of LZ-205, more and more nuclear disintegration occurred along with DNA fragmentation.

LZ-205-induced apoptosis was further assessed by AnnexinV/PI staining (Figure 2C). A comparison with the control group $(2.29 \pm 0.96 \%)$, revealed that the early apoptotic rate of LZ-205-treated $(4,6$, and $8 \mu \mathrm{M})$ cells was increased to $16.33 \pm 4.79 \%, 31.79 \pm 4.70 \%$, and $39.92 \pm$ $1.63 \%$, respectively. Additionally, the late apoptotic rate of cells treated with the same amounts of LZ-205 pointed toward the same trend. The early and late apoptotic rates of Wogonin-treated $(120 \mu \mathrm{M})$ cells were $14.59 \pm 2.74 \%$ and $18.63 \pm 0.24 \%$, respectively. In addition, the apoptosis inducing effects of LZ-205 were also found in other human lung cancer cells, such as A549 and GLC82, as shown in Supplementary Figure S1A.

Taken together, these results indicate that LZ-205 induces apoptosis in human lung cancer cells.

\section{The mitochondrial dependent pathway and exogenous apoptotic pathway are involved in LZ-205-induced apoptosis}

The change in mitochondrial membrane potential (MMP) change is a crucial stage in drug-induced apoptosis. The results of the MMP measurement showed a considerable decrease of the MMP level in LZ-205-treated cells (Figure 3A and Supplementary Figure S1B). The levels of Cyt-c were significantly increased in the cytosol of cells treated with LZ-205 for $24 \mathrm{~h}$, whereas they were decreased in mitochondria (Figure 3B). Apoptosis inducing factor (AIF) in the LZ-205-treated group was also found to be decreased in mitochondria and increased in nucleus, which suggested that AIF was transferred to the nucleus from mitochondria. In addition, western blot analysis was conducted to further evaluate the effects of LZ-205-induced apoptosis on protein expression. The results of the analysis showed that cleaved-caspase 9, cleaved-caspase 3, Bim, Noxa, Bax were significantly upregulated, whereas the levels of pro-caspase 9, pro-caspase 3 and Bcl-2 were downregulated (Figure 3C). These results indicated that LZ-205 induces a mitochondrial dependent apoptotic pathway. At the same time, we found the cleaved-caspase 8, Fas and FasL levels were also increased, while expression of pro-caspase 8 and BID were decreased (Figure 3D), which indicated the activation of the extrinsic apoptotic pathway. To prove that LZ-205-induced apoptosis is caspase-dependent, we investigated the effect of Z-VADFMK, a pan caspase inhibitor. Additionally, Z-IETD-FMK, a caspase 8 inhibitor, was used to further verify the activating effect of LZ-205 on the extrinsic apoptotic pathway. The flow cytometry analysis showed that Z-IETD-FMK and Z-VADFMK suppressed LZ-205-induced apoptosis in NCI-H460 cells $(71.58 \pm 2.64 \%$ in the LZ-205 group vs. $45.10 \pm 0.67 \%$ in the Z-IETD-FMK+LZ-205 group and $24.58 \pm 1.28 \%$ in the Z-VAD-FMK+LZ-205 group), as shown in Figure $3 \mathrm{E}$. These results suggested that LZ-205 induced both caspase 8 dependent and independent apoptotic pathway. Furthermore, immunohistochemistry (IHC) analysis of tissue samples revealed a significant up-regulation of FasL expression in the LZ-205-treated group and confirmed the occurrence of Fas-mediated apoptosis in vivo (Figure 3F).

Based on the above results, we concluded that LZ205 induces both the intrinsic or mitochondrial apoptotic pathway and the extrinsic apoptotic pathway.

\section{LZ-205-induced ROS lead to apoptosis}

The rise of the level of ROS can result in ER stress, mitochondrial dysfunction and ultimately apoptosis [7]. 
To assess the effects of LZ-205 on ROS induction, we determined the production of ROS using a carboxy- $\mathrm{H}_{2}$ DCFDA probe, which can be converted to a green fluorescent product, carboxy-DCF, by oxidation. The results suggested that LZ205 upregulated the level of ROS in NCI-H460 cells, as shown in Figure 4A. Additionally, the same phenomenon was detected in A549 and GLC82 cells (Supplementary Figure S1C). N-acetylcysteine (NAC), a ROS scavenger, was used to further examine whether ROS effected the induction of apoptosis by LZ-205. The results revealed that the level of ROS induced by LZ-205 was partly reduced by NAC (Figure 4A). In addition, Annexin V/PI staining showed that NAC partly inhibited the LZ-205-induced apoptosis $(70.95 \pm 8.66 \%$ in the
LZ-205 group vs. $22.19 \pm 8.62 \%$ in the NAC+LZ-205 group, Figure 4B and 4C). Thus, these results indicated that LZ-205 increased the level of ROS, which in turn could be partly responsible for the induction of apoptosis.

\section{Involvement of ER stress in LZ-205-induced apoptosis}

The ER stress-induced apoptosis is always accompanied by $\mathrm{Ca}^{2+}$ overloading [9]. The level of $\mathrm{Ca}^{2+}$ is shown in Figure 5A and Supplementary Figure S1D. A concentration-dependent increase in $\mathrm{Ca}^{2+}$ level was observed in LZ-205 treated cells. To determine the impact

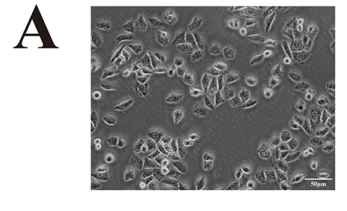

Control

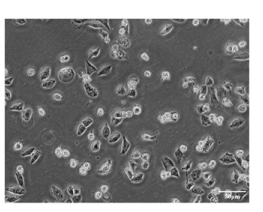

Wogonin $120 \mu \mathrm{M}$

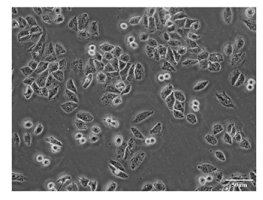

4

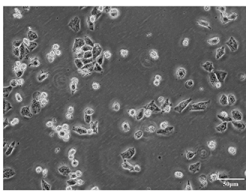

6

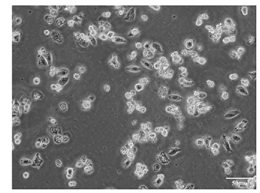

8

B

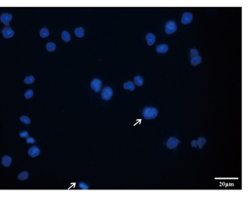

Control

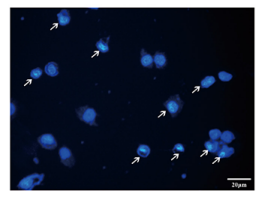

Wogonin $120 \mu \mathrm{M}$

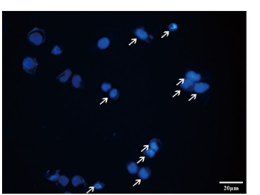

4

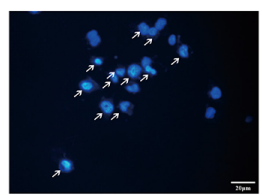

6

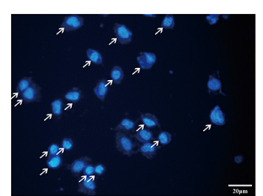

8

8

LZ-205 ( $\mu \mathrm{M})$
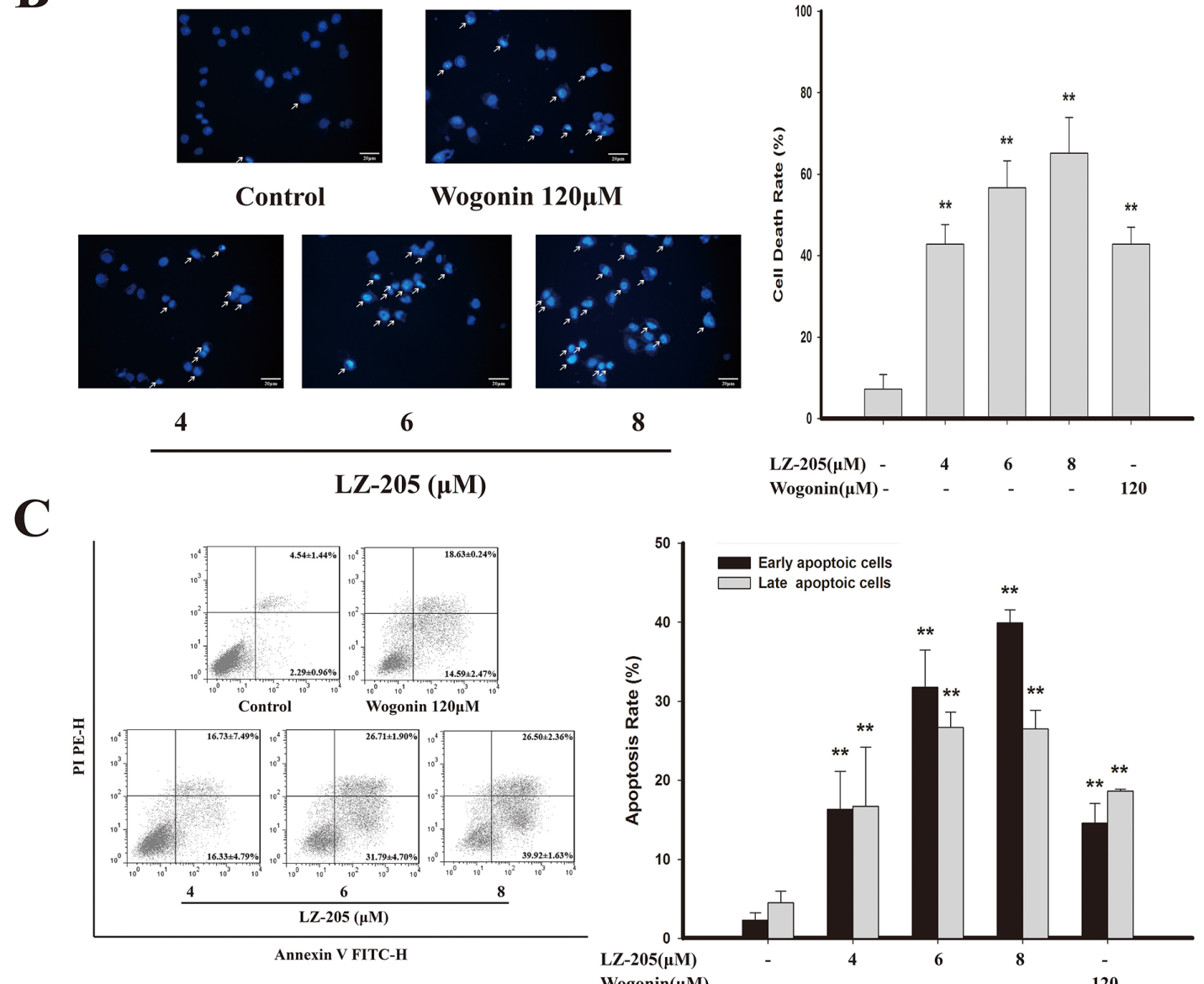

$\operatorname{Wogonin}(\mu \mathrm{M})$ - $\quad-\quad \quad-\quad-\quad 120$

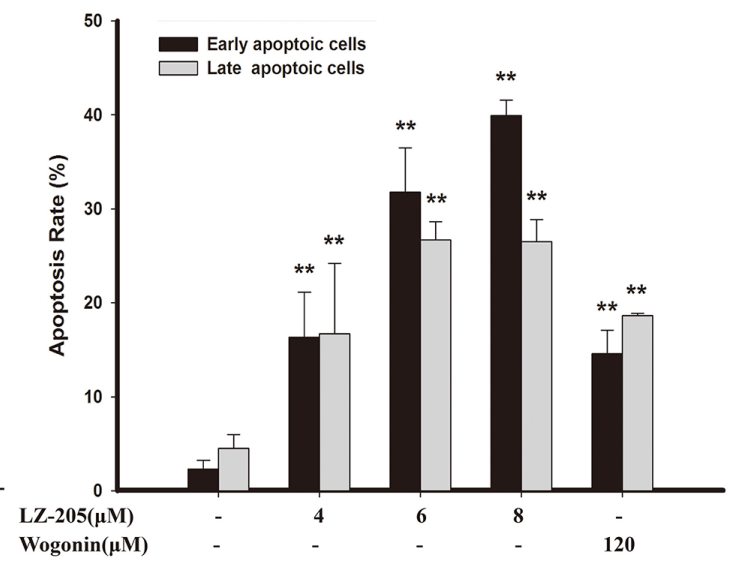

Figure 2: Apoptosis induced by LZ-205 in NCI-H460 cells. Cells were treated with 4, 6 and $8 \mu$ M LZ-205 for $24 \mathrm{~h}$. A. Observed under an inverted light microscope $(200 \times)$. B. Stained with DAPI $(400 \times)$. White arrow pointed to dead cells and cell death rate was analyzed. C. Annexin V/PI double-staining assay of NCI-H460 was analyzed by flow cytometry. Data were shown as Means \pm SD for three independent experiments $\left({ }^{*} p<0.05\right.$ and ${ }^{* *} p<0.01$ compared with Control). 
of ER stress on LZ-205-induced apoptosis, western blot analysis of regarding ER stress pathway-related proteins expression was conducted. The results indicated that LZ-205 induced the protein expression levels of GRP78, p-PERK and p-EIF2 $\alpha$, ATF 4 , p-IRE1 $\alpha$, XBP- 1 and CHOP (Figure $5 \mathrm{C}$ ). We also found increased expression levels of GRP78 and CHOP in A549 and GLC82 cells (Supplementary Figure S1E). An active spliced form of XBP1 (XBP1s), that triggers a distinct set of UPR-induced genes, which participate in protein folding in the ER, represents a major event triggering UPR signaling [14]. Accordingly, we evaluated the splicing of $X B P 1$ by quantitative realtime PCR and found that spliced XBPI mRNA level was clearly increased by LZ-205, which indicated IRE1-XBP-1 pathway were activated (Figure 5B). Overall these data suggested that LZ-205 triggers ER stress.

To further examine the role of ER stress in LZ-205induced apoptosis, LZ-205-treated NCI-H460 cells were transiently transfected with control-siRNA or CHOP-siRNA and analyzed for apoptosis. The data shown in Figure 5D demonstrated a successful transfection. Additionally, CHOP-siRNA pretreatment significantly suppressed the LZ-205-induced apoptosis $(69.24 \pm 0.59 \%$ in the LZ$205+$ control-siRNA -treated group vs. $34.69 \pm 7.04 \%$ in the LZ-205+CHOP-siRNA-treated group). The results indicated that CHOP promoted LZ-205-induced apoptosis.
A

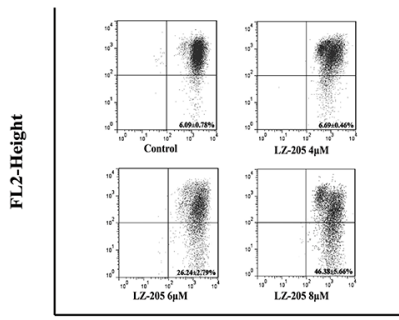

FL1-Height

C

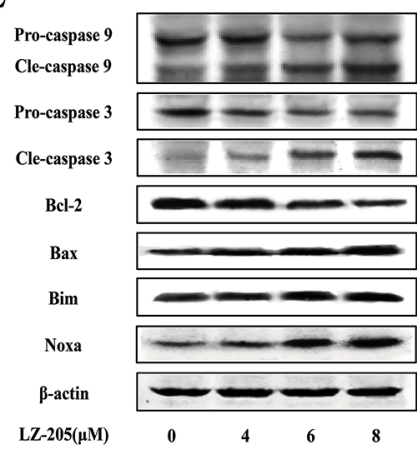

E

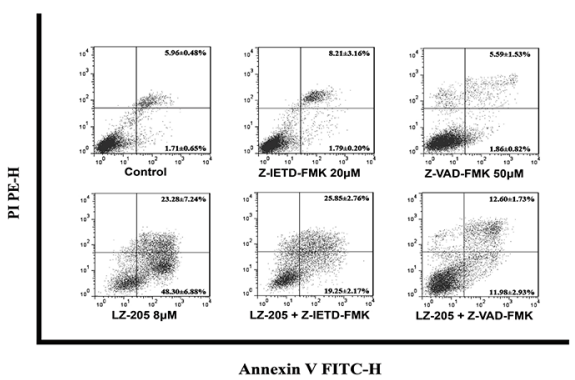

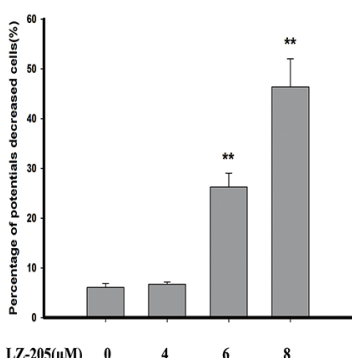

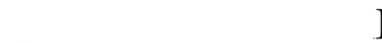

B

$\mathrm{D}$

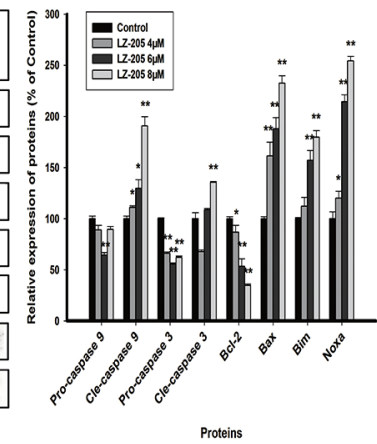

Proteins

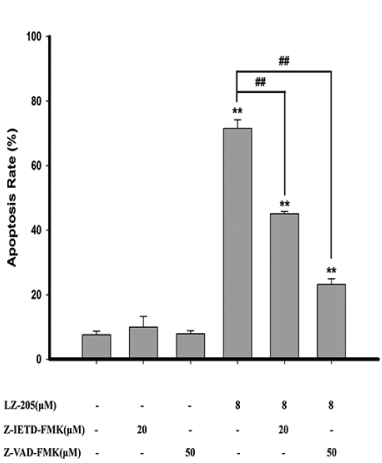

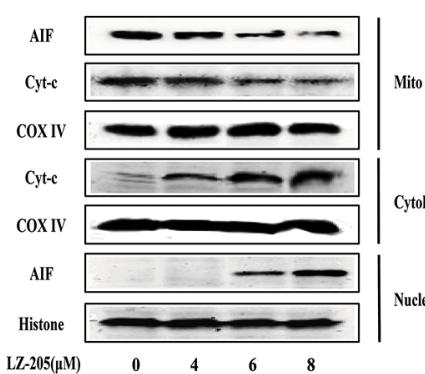
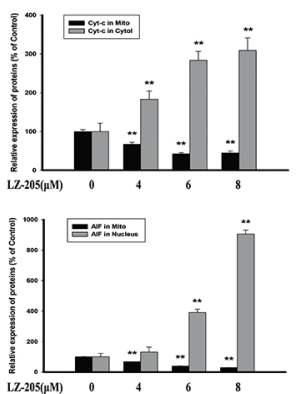

Pro-caspase 8

Cle-caspase 8

Fas

FasL

Bid

$\beta$-actin

LZ-205( $\mu \mathrm{M})$
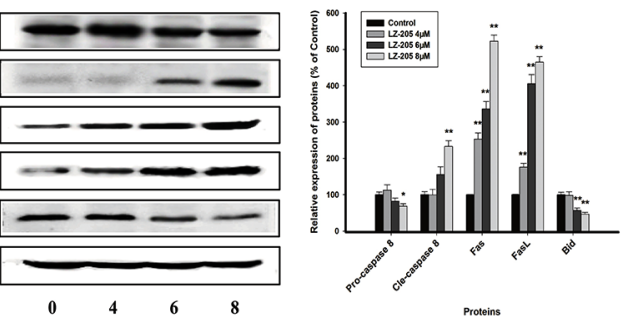

F
FasL

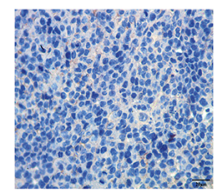

Control

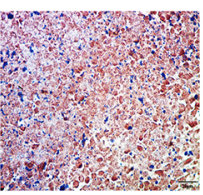

LZ-205 40mg/kg

Figure 3: LZ-205 activates the mitochondrial apoptotic pathway and exogenous apoptotic pathway. Cells were exposed to LZ-205 (4, 6 and $8 \mu \mathrm{M})$ for $24 \mathrm{~h}$. A. Cells were stained with JC-1 and detected by flow cytometry. Then the percentage of $\Delta \Psi \mathrm{m}$ collapsed cells was analyzed. B. Effect of LZ-205 on Cyt-c and AIF in NCI-H460 cells. Mitochondrial, cytosolic and nuclei fractions were subjected to western blot analysis. C. The protein of Caspase 9, Caspase 3, Bcl-2, Bax, Bim and Noxa were analyzed by western blotting. D. The protein of Caspase 8, Fas, FasL and BID were analyzed by western blotting. E. Cells were treated with/without $20 \mu \mathrm{M}$ Z-IETF-FMK (a caspase 8 inhibitor), $50 \mu \mathrm{M}$ Z-VAD-FMK (a pan caspase inhibitor) and $8 \mu \mathrm{M} \mathrm{LZ-205} \mathrm{for} 24 \mathrm{~h}$. The apoptosis were analyzed with flow cytometry. F. Immunohistochemical detection of FasL protein level in mouse transplantation tumor tissues $(100 \times)$. Results were means \pm SD for at least three independent experiments $\left({ }^{*} p<0.05\right.$ and ${ }^{* *} p<0.01$ compared with Control). 
In addition, NAC was used to reduce the ROS level and then the ER stress was evaluated. The results showed that NAC inhibited the LZ-205 upregulated expression of GRP78 and CHOP as shown in Figure 5E, which made it clear that LZ-205-induced ROS trigger the ER stress. Furthermore, the tissue sample IHC results revealed higher expression of the protein of GRP78 and CHOP in the LZ205-treated group (Figure 5F).

All the above data verified that LZ-205 triggered ER stress in vivo and in vitro.

\section{LZ-205 exhibited potential anti-tumor effect with low toxicity in vivo}

A nude mouse model bearing inoculated H460 tumor was utilized to assess the antitumor effect of LZ-205 in vivo. The measured tumor volume further confirmed the significant reduction of the tumor size in the LZ-205 treatment group. Indeed, the 21-day treatment with LZ-205 (10, 20 and $40 \mathrm{mg} / \mathrm{kg})$ or Wogonin $(60 \mathrm{mg} / \mathrm{kg})$ showed significant inhibitory effects on the
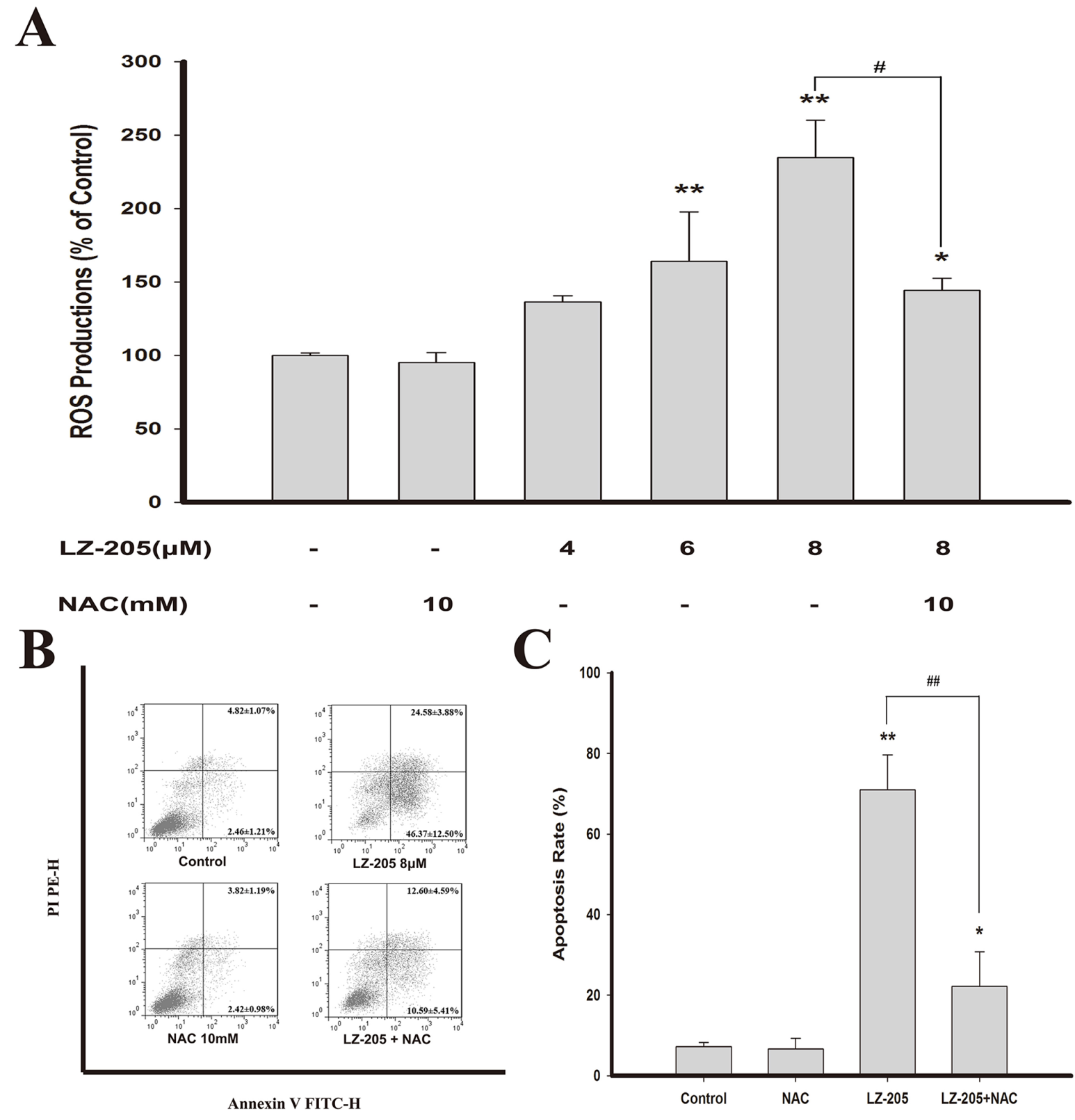

8

8

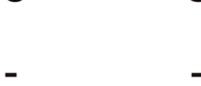

10
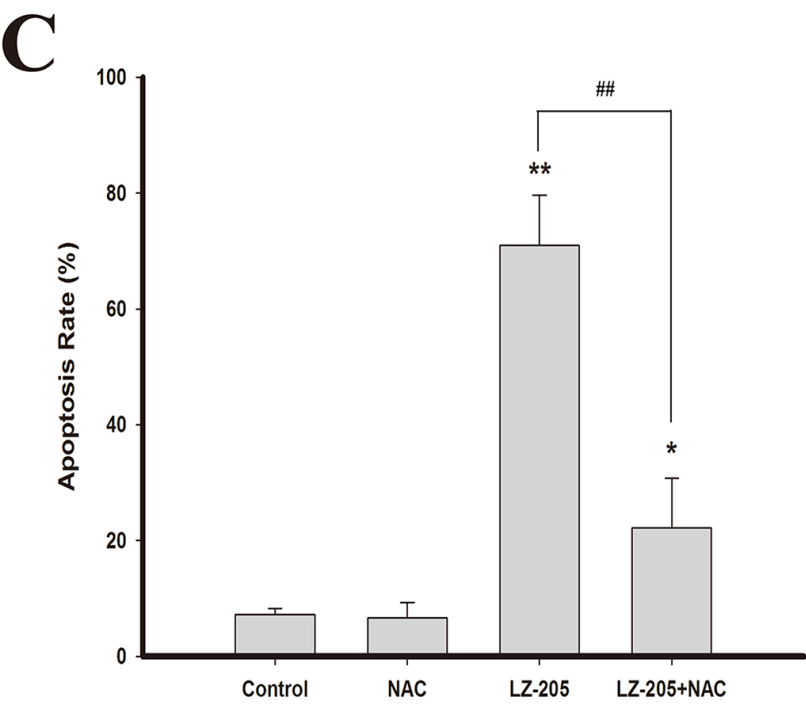

Figure 4: LZ-205 increased the level of ROS. A. Cells were pretreated with/without $10 \mathrm{mM} \mathrm{NAC} \mathrm{for} 1 \mathrm{~h}$, and then exposed with/ without LZ-205 for $12 \mathrm{~h}$. Finally, the ROS level was detected by flow cytometry. B and C. Cells were pretreated with/without $10 \mathrm{mM}$ NAC for $1 \mathrm{~h}$, and then treated with/without $8 \mu \mathrm{M} \mathrm{LZ}-205$ for $24 \mathrm{~h}$. The apoptosis were analyzed with flow cytometry. Values were Means \pm SD for at least three independent experiments $\left({ }^{*} p<0.05\right.$ and ${ }^{* *} p<0.01$ compared with Control; ${ }^{*} p<0.05$ and ${ }^{\#} p<0.01$ compared with LZ-205 treated group). 


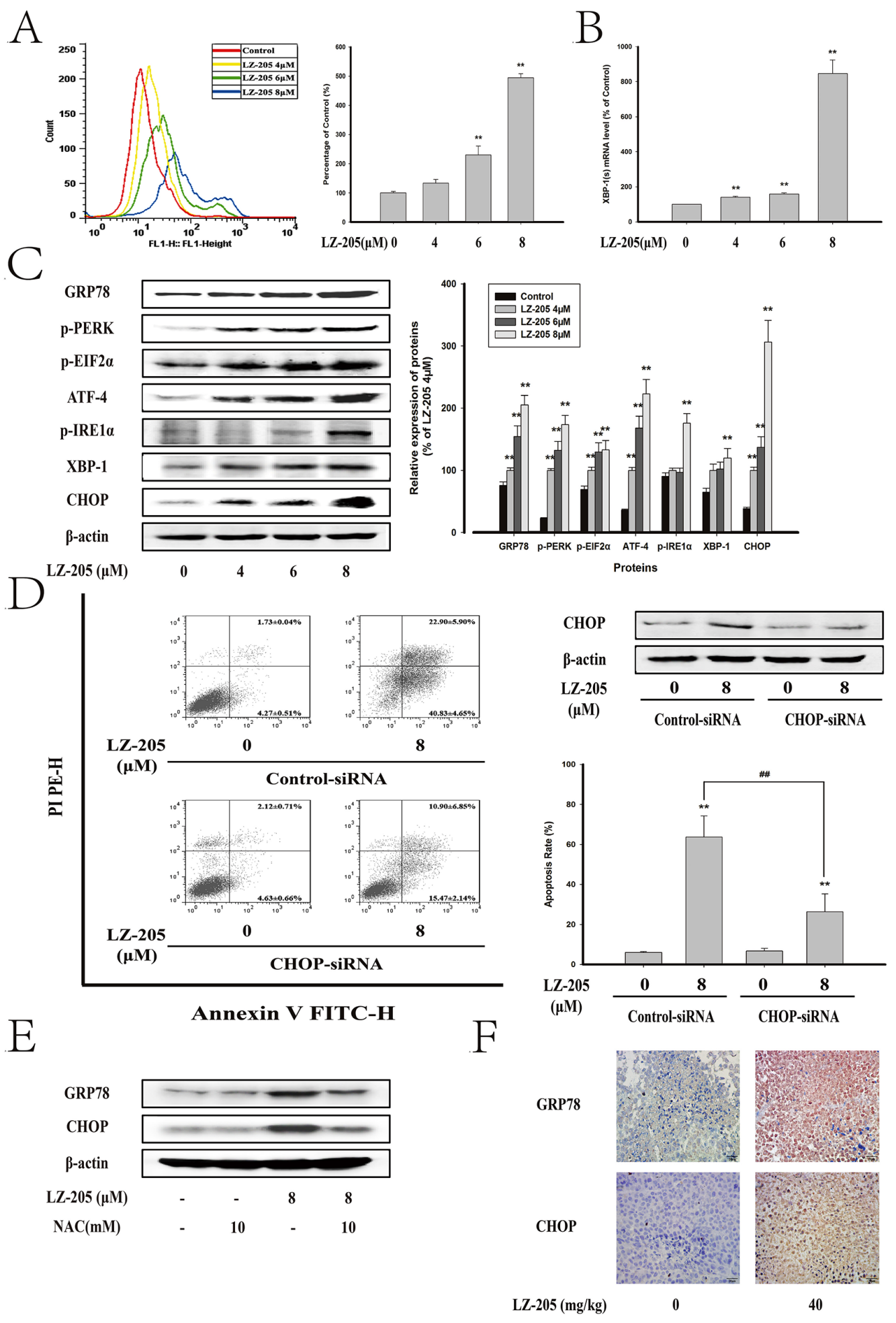

Figure 5: LZ-205 induced apoptosis by initiating ER Stress. Cells were treated with 4, 6 and $8 \mu \mathrm{M} \mathrm{LZ-205} \mathrm{for} 24 \mathrm{~h} \mathrm{~A}$. The Ga ${ }^{2+}$ level was detected by flow cytometry. B. LZ-205 induced alternative splicing of XBP1 mRNA. It was analyzed by Quantitative real-time PCR. C. The protein of GRP78, p-PERK, p-EIF2 $\alpha$, ATF-4, p-IRE1 $\alpha$, XBP-1 and CHOP were analyzed by western blotting. D. Cells were transfected with control-siRNA or CHOP-siRNA and incubated for $8 \mathrm{~h}$, and then treated with/without $8 \mu \mathrm{M} \mathrm{LZ}-205$ for $24 \mathrm{~h}$. The protein of CHOP was detected by western blotting. Then the apoptosis rate was detected by Annexin V/PI double staining. E. Cells were pretreated with/without $10 \mathrm{mM} \mathrm{NAC}$ for $1 \mathrm{~h}$, and then treated with/without $8 \mu \mathrm{M} \mathrm{LZ}-205$ for $24 \mathrm{~h}$. The expression of GRP78 and CHOP were analyzed by western blotting. F. Immunohistochemical detection of GRP78 and CHOP protein levels in mouse transplantation tumor tissues (100×). Data were Means $\pm \mathrm{SD}$ for three independent experiments $\left({ }^{*} p<0.05\right.$ and ${ }^{* *} p<0.01$ compared with Control or Control-siRNA-transfected group; ${ }^{*} p<0.05$ and ${ }^{\# \#} p<0.01$ compared with LZ-205 + Control-siRNA treated group). 
growth of inoculated H460 tumors in mice (Figure 6A). Additionally, as shown in Figure 6B, LZ-205 inhibited the weight of the tumor, which was decreased by $61 \%$ in the group treated with $40 \mathrm{mg} / \mathrm{kg}$ of LZ-205. A similar effect was observed with $60 \mathrm{mg} / \mathrm{kg}$ Wogonin regimen, which showed an inhibitory rate of $58 \%$. Treatment with LZ-205 at $10 \mathrm{mg} / \mathrm{kg}$ and $20 \mathrm{mg} / \mathrm{kg}$ resulted in $16 \%$ and $39 \%$ of tumor weight loss respectively. Compared with the control group, tumor volume in the LZ-205
$(10,20$, and $40 \mathrm{mg} / \mathrm{kg})$ and Wogonin $(60 \mathrm{mg} / \mathrm{kg})$ groups decreased by $18.31 \%, 24.87 \%, 43.52 \%$, and $35.66 \%$, respectively (Figure 6C). The TUNEL assay was used to analyze the apoptotic cells in the tumor tissues. Increased fluorescence signal indicated the extent of DNA damage induced by LZ-205 (Figure 6D). These results demonstrated that LZ-205 inhibited the growth of the transplanted tumors by inducing apoptosis in a dosedependent manner.
A

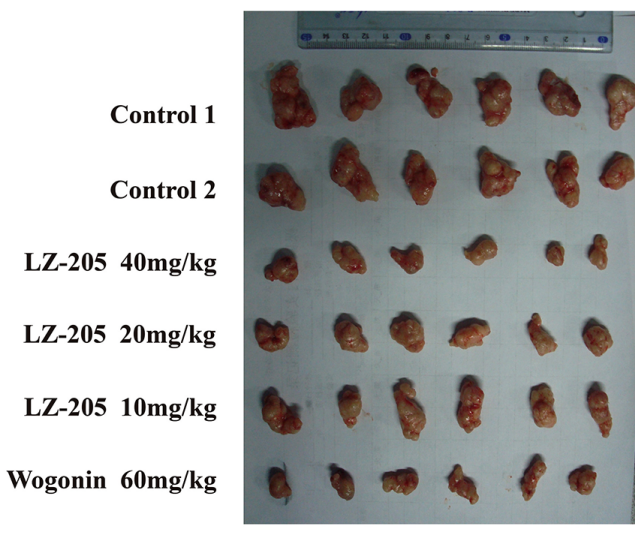

C

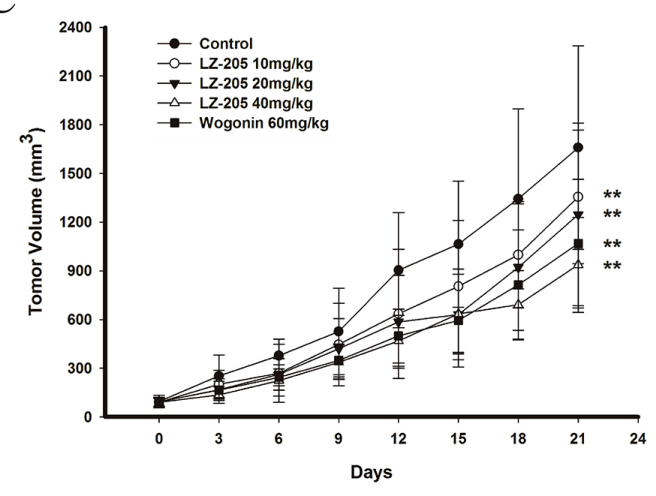

E

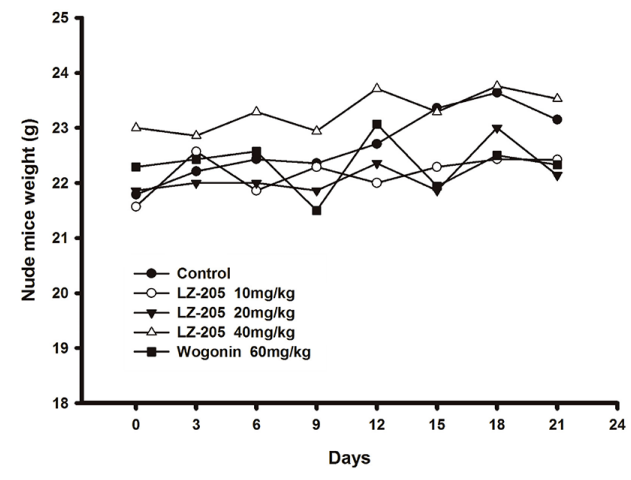

B

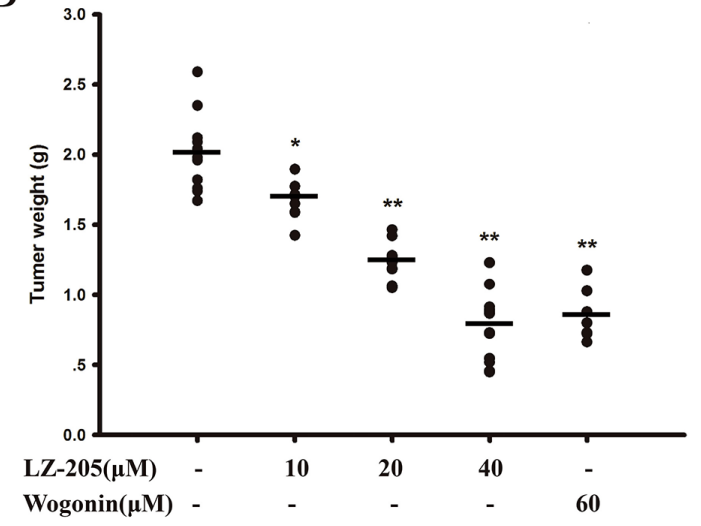

D

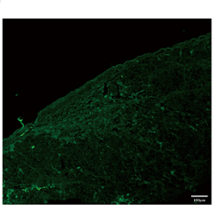

Control

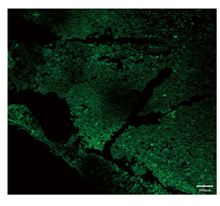

LZ-205 10mg/kg

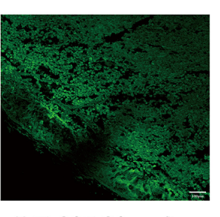

LZ-205 20mg/kg

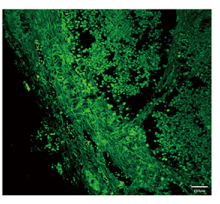

LZ-205 40mg/kg

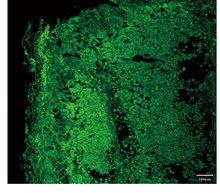

Wogonin $60 \mathrm{mg} / \mathrm{kg}$

F

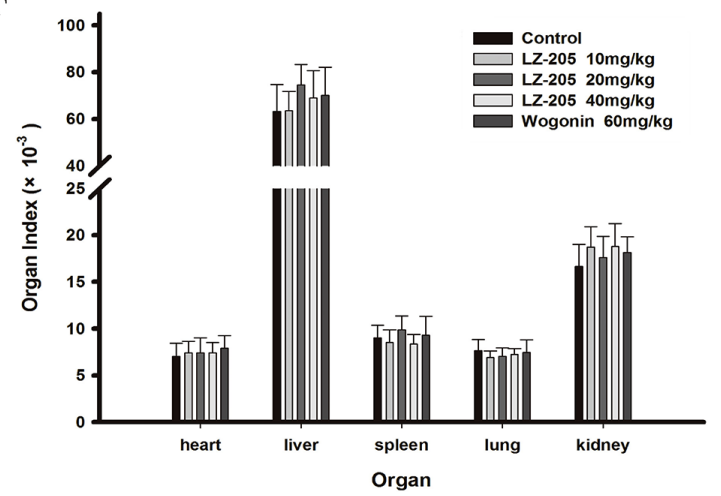

Figure 6: LZ-205 has a potential antitumor effect and low toxicity in vivo. The transplanted mice NCI-H460 no-small cell lung cancers were treated with 10,20 and $40 \mathrm{mg} / \mathrm{kg}$ of LZ-205 and $60 \mathrm{mg} / \mathrm{kg}$ of wogonin by i.v. once every two days. Control group was treated with normal saline. A. Resected human non-small lung cancer tumor images from the experimental. B. The tumor weights were tested. C. Tumor volume results $(100 \times)$ were given as Means \pm SD. D. Detected the DNA damage with TUNEL assay. E. Nude mice weight was recorded once every three days. F. Main organs index of mice (organ weight/body weight) was used to evaluate the toxicity of LZ-205 
Table 1: Hematology profile in non-tumor bearing athymic nude mice administered with normal saline

\begin{tabular}{|c|c|c|c|c|c|}
\hline Hematological parameters & Control & $10 \mathrm{mg} / \mathrm{kg}$ & $20 \mathrm{mg} / \mathrm{kg}$ & $40 \mathrm{mg} / \mathrm{kg}$ & standard \\
\hline White blood cells $\left(\times 10^{\wedge} 3 / \mu \mathrm{L}\right)$ & $4.97 / 5 / 7.59$ & $6.07 / 5.25 / 6.64$ & 3.56/5.54/N.D. & 4.8/5.53/N.D. & $4.5-9.1$ \\
\hline Platelet $\left(\times 10^{\wedge} 3 / \mu \mathrm{L}\right)$ & $716 / 978 / 652$ & $1012 / 748 / 758$ & $1082 / 349 / 1258$ & $757 / 740 / 1011$ & $115-1037$ \\
\hline Band neutrophils(\%) & $0 / 0 / 0$ & $0 / 0 / 0$ & $0 / 0 / 0$ & $0 / 0 / 0$ & $0-1$ \\
\hline Lymphocytes(\%) & $49.34 / 53.04 / 48.14$ & $57.44 / 57 / 4 / 50.8$ & $52.3 / 46.5 / 63.2$ & $62.1 / 54.5 / 55$ & $49-82$ \\
\hline Eosinophils(\%) & $0.04 / 0.04 / 0.04$ & $0.04 / 0.04 / 0.04$ & $0.24 / 0.04 / 0.04$ & $0.04 / 0.24 / 0.04$ & $0-3$ \\
\hline Monocytes & $4.74 / 4.44 / 3.64$ & $4.94 / 4.84 / 5.44$ & $7.14 / 9.04 / 7.94$ & $6.74 / 5.14 / 4.44$ & $2-8$ \\
\hline Mean corpuscular volume (fL) & $51.6 / 49.4 / 49.3$ & $50.9 / 47.5 / 52.4$ & $47.5 / 51 / 50$ & $49.7 / 47.2 / 51.1$ & $41-60$ \\
\hline Hematocrit (\%) & $43.9 / 46 / 43.1$ & $44.2 / 43 / 48.9$ & $50.2 / 49.2 / 42.9$ & $47.9 / 46.8 / 44.1$ & $34-50$ \\
\hline Basophils (\%) & $0.04 / 0.24 / 0.04$ & $0.04 / 0.04 / 0.04$ & $0.04 / 0.04 / 0.44$ & $0.04 / 0.24 / 0.4$ & $0-3$ \\
\hline Mean corpuscular hemoglobin (pg) & $15.9 / 14.6 / 15.3$ & $15.6 / 14.6 / 15.3$ & $15.3 / 14.1 / 15.3$ & $14.5 / 15.4 / 15.3$ & $13-19$ \\
\hline $\begin{array}{l}\text { Mean corpuscular hemoglobin } \\
\text { concentration }(\%)\end{array}$ & $30.8 / 29.6 / 31.1$ & $30.5 / 30.7 / 29.2$ & $30.1 / 31.1 / 30.3$ & $30.5 / 30.1 / 30.6$ & $30-39$ \\
\hline Red blood cells $\left(\times 10^{\wedge} 3 / \mu \mathrm{L}\right)$ & $8.5 / 9.32 / 8.75$ & $8.68 / 9.05 / 9.33$ & $9.9 / 10.82 / 8.52$ & $10.08 / 9.17 / 8.82$ & $7.51-9.66$ \\
\hline Hemoglobin (g/dl) & 13.5/13.6/13.4 & 13.5/13.2/14.3 & $15.1 / 15.3 / 13$ & 14.6/14.1/13.5 & $12.8-16.1$ \\
\hline
\end{tabular}

Three mice per group were used. Standard ranges were obtained in house from 100 normal BALB/c mice of $8-12$ weeks age.

Meanwhile, measurement and calculation of the mice weight and organ index revealed no significant change in any group (Figure 6E and 6F). In addition, hematological parameters results also indicated that there were no noticeable changes in the analyzed parameters in the tested animals and the standard ranges for the mice are listed in Table 1.

In conclusion, LZ-205 inhibited the growth of H460 xenografts in nude mice in a dose-dependent manner without major side-effects. Additionally, the compound could dramatically induce apoptosis in vivo.

\section{DISCUSSION}

Currently, more and more attention has been paid to flavonoids, like wogonin, as a novel source of anticancer drugs and new chemotherapy adjuvants to improve the efficacy of chemotherapeutic agents and to diminish their side effects. Wogonin induces apoptosis in hepatocellular carcinoma cells through the caspase 3 pathway and alternative expression of p21 protein [15-17] or by activating other pathways $[18,19]$. In addition, many wogonin derivatives have been reported to possess potential anti-tumor properties, such as LYG-202, LW-214, etc. [20, 21]. As a new flavonoid compound similar in structure to Wogonin, LZ-205 induced lung cancer cell apoptosis in the present study. Actually, the apoptotic effect of $8 \mu \mathrm{M}$ of LZ-205 treatment was stronger than that of $120 \mu \mathrm{M}$ of Wogonin ( $66 \%$ vs. $33 \%$ ). In the nude mouse model, LZ-205 exhibited the same growth inhibition ability as Wogonin. Although according to the National Comprehensive Cancer Network (NCCN) Guidelines for lung cancer, chemotherapy regimens, including platinum drugs, will prolong survival and improve symptom control, their use can be limited by granulocyte and platelet inhibition and renal toxicity. LZ-205 was found to have no significant influence on the hematological system and mice normal tissues, suggesting a potential low toxicity compared with traditional chemotherapeutic drugs. Moreover, LZ-205 is more water solubility than Wogonin, which makes it easier to be developed into a clinical drug.

ROS could be generated in diverse biological systems, and they also served as important determinants in cell signaling pathways involved in regulating proliferation, apoptosis and senescence. Above all, ROS is an important mediator of various chemotherapeutic agents [22]. Yu, J. Q. found that Wogonin altered ROS levels and induced cell death in human hepatoma cells [23]. In our study, LZ205 increased the intracellular levels of ROS and induced apoptosis in human lung cancer cells, both of which were attenuated by the addition of NAC, a ROS scavenger. Oxidative stress is defined as a condition with an impaired prooxidant/antioxidant balance in a cell. Once cellular biomolecules confront severe oxidative damage, cell viability would be promoted [24]. ROS increase the level of oxidized proteins, which are identified as misfolded proteins in the ER and eventually trigger the UPR pathway. Meanwhile, LZ205 increased the level of $\mathrm{Ca}^{2+}$, which is also implicated in the depletion of ER calcium. These findings indicate that ER stress could be involved in LZ-205-induced apoptosis. ER stress triggers apoptosis through two distinct mechanisms: one is the alteration in intracellular calcium levels and the 
other one is the accumulation of unfolded or misfolded proteins [25]. Actually, the PERK-EIF2 $\alpha$-ATF4 and IRE1 $\alpha-$ XBP1 pathways were activated by LZ-205. CHOP is an important target gene driven by ATF4 and XBP1 and a proapoptotic transcription factor that reduces $\mathrm{Bcl}-2$ and promotes the translocation of Bax [26, 27]. Silencing of the CHOP expression also reduced the LZ-205-triggered apoptosis induced by ER stress in lung cancer cells.

The intrinsic or mitochondrial apoptotic pathway plays a key role in accomplishing ER stress-induced apoptosis, and the collapse of the membrane potential $(\Delta \Psi \mathrm{m})$ is considered to be a hallmark of this pathway. Mitochondrial dysfunction induces the release of Cyt-c from the mitochondria, which triggers the caspase-dependent pathway and ultimately causes apoptosis [28]. AIF, another pro-apoptosis protein, translocates from the mitochondria to the nucleus, where it leads to DNA fragmentation and chromatin condensation [29]. Our study found that LZ-205 caused a decrease in the $\Delta \Psi \mathrm{m}$, couple with a release of Cyt-c and a nuclear translocation of AIF, which suggested that the intrinsic pathway takes part in the LZ205 induced apoptosis. The proteins of the Bcl-2 family are key regulators of apoptosis and a slight imbalance of these proteins may lead to either inhibition or promotion of cell death. The ratio of Bax/Bcl-2 usually represents the extent of mitochondrial outer membrane permeabilization [30]. Accordingly, we investigated the Bcl-2 family of proteins to further evaluate the effect of LZ-205 on mitochondria. The results showed that LZ-205 increased the ratio of Bax/Bcl2 and the expression of Bim and Noxa, which have been proven to induce Cyt-c release. Besides, a decrease of procaspase 9 and 3 suggested a caspase cascade was activated by LZ-205. Ultimately, we concluded that mitochondrial dysfunction contributed to LZ-205 induced apoptosis.

Noteworthy, neither NAC nor CHOP-siRNA can completely reverse the LZ-205-induced apoptosis. We speculated that there must be a pathway independent of ROS and ER stress involved in LZ-205-induced apoptosis. Previous studies found that Wogonin induces apoptosis through the Fas-related extrinsic signaling pathways in human osteosarcoma U-2 OS cells [18] and human leukemia CEM T cells $[31,32]$. In the present study, LZ-205 also increased Fas and FasL expression and subsequently activated caspase 8 . Moreover, pretreatment with a caspase 8 inhibitor significantly increased cell viability in the LZ-205-treated NCI-H460 cells. In addition, LZ-205 consistently increased truncated BID (tBID) levels which is normally the result of caspase 8 activation [33]. Thus, LZ-205 also triggers the extrinsic apoptotic pathway. Further research on the death receptor pathway including Fas, TNF $\alpha$ and Trail is in ongoing.

In conclusion, our study revealed that LZ-205 inhibits the growth of lung cancer via the induction of apoptosis in vivo and in vitro. LZ-205 triggered ROSmedicated ER stress thereby inducing apoptosis, as shown in Figure 7. Additionally, the extrinsic apoptotic pathway

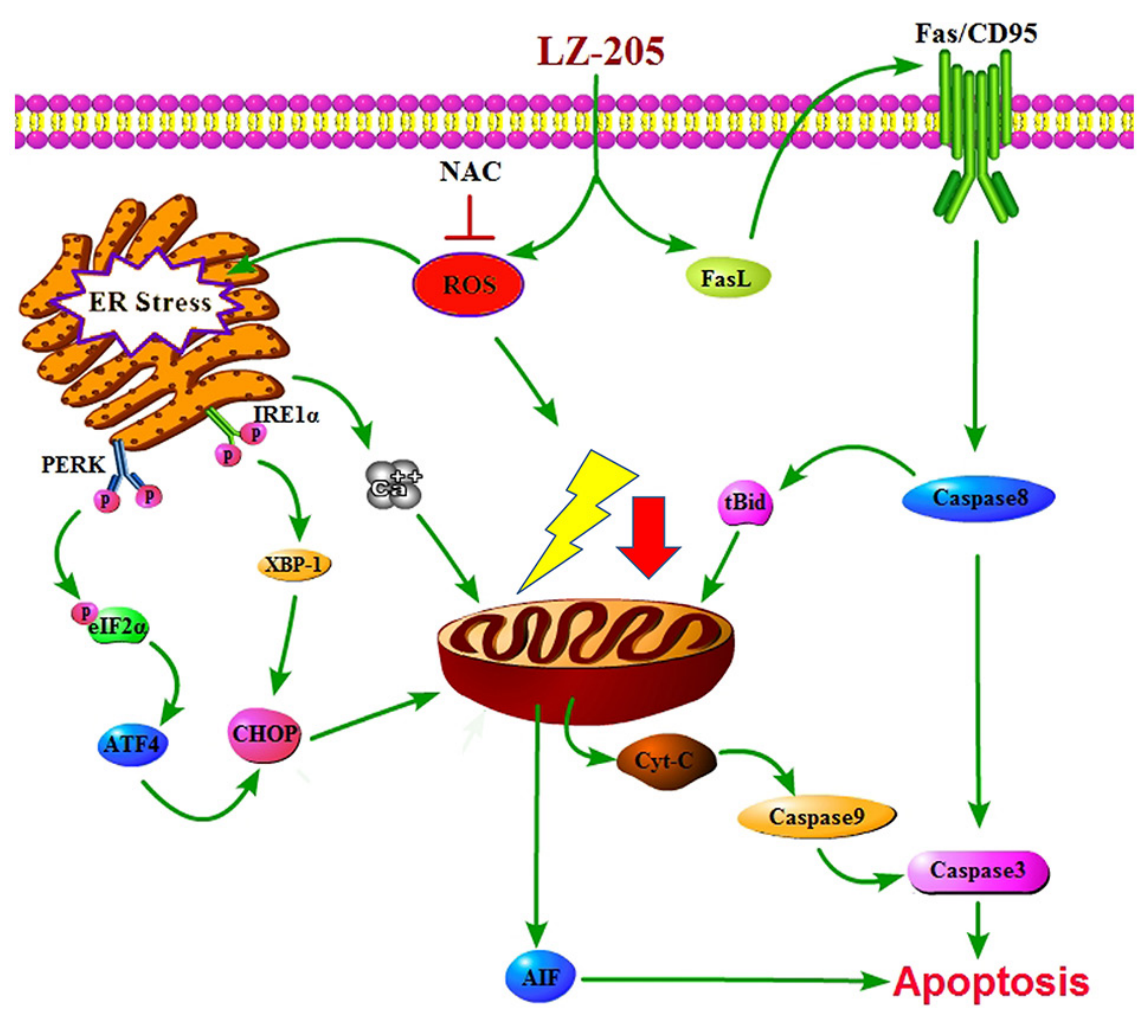

Figure 7: Schematic model for the mechanisms of LZ-205-induced apoptosis in human lung cancer cells. LZ-205 induces apoptosis through multiple apoptotic pathways, including extrinsic apoptotic pathway and ROS-mediated-ER stress-dependent pathway. 
was found to be involved in this process. Our research provides a detailed explanation of the effect of LZ-205 on lung cancer cells and the molecular mechanism involved, and proposes this compound as a promising therapeutic agent against lung cancer in humans.

\section{MATERIALS AND METHODS}

\section{Cell culture and reagents}

The human non-small lung cancer NCI-H460 and A549 cell lines and human poorly differentiated lung adenocarcinoma GLC82 cell line were purchased from Cell Bank of Shanghai Institute of Biochemistry and \& Cell Biology, Chinese Academy of Sciences. Cells were cultured in RPMI-1640 medium (Gibco, Thermo Fisher Scientific, USA) containing $10 \%$ fetal bovine serum (Gibco, Thermo Fisher Scientific, USA), 100 units/mL penicillin and $100 \mu \mathrm{g} / \mathrm{mL}$ streptomycin. Exponentially growing cultures were maintained in a humidified atmosphere of $5 \% \mathrm{CO}_{2}$ at $37^{\circ} \mathrm{C}$.

LZ-205 (purity 99.31\%) was applied in sterile water to $0.01 \mathrm{M}$ and stored at $-20^{\circ} \mathrm{C}$. The concentrations used here were 4,6 and $8 \mu \mathrm{M}$ in vitro, and freshly diluted with sterile water to final con-centration. MTT [3-(4, 5-dimethylthiazol-2-yl)-2, 5-diphenytetrazoliumbromide] (Ronkonkoma, NY) was dissolved in $0.01 \mathrm{M}$ PBS. Z-IETD-FMK and Z-VAD-FMK were obtained from Selleck (Shanghai, China) and was dissolved in DMSO to $5 \mathrm{mM}$. N-acetyl-L-cysteine (NAC) was obtained from Sigma-Aldrich (USA) and dissolved in sterile water. Primary antibodies of ATF4, BID, Cyt-c, eIF2 $\alpha$, Noxa, PERK, p-PERK, p-eIF2 $\alpha$, Caspase 3, Caspase 8, Caspase 9, and $\beta$-actin were purchased from Santa Cruz Biotechnology (California, USA). Antibodies of AIF, Bim, and CHOP were purchased from Cell Signaling Technology (Beverly, MA, USA). Antibodies including Bax, Bcl-2, COX-IV, Fas, FasL, GRP78 and Histones were the purchased from Bioworld (USA). Annexin V-FITC Apoptosis Detection Kit was purchased from Vazyme (Nanjing, China).

\section{Cell viability assay}

Cells were seeded into 96-well plates with $1 \times 10^{4}$ / well in $100 \mu \mathrm{L}$ culture medium. LZ-205 were dissolved into sterile water and added into cells at different concentration. Cells were incubated with LZ-205 for $24 \mathrm{~h}$ before MTT assay [34].

\section{DAPI staining}

Cells were cultured in 6-well tissue culture plates and then treated with the indicated concentration of drug in $24 \mathrm{~h}$. At the end of incubation, the cells were fixed, washed with PBS and incubated with DAPI $(1 \mu \mathrm{g} / \mathrm{mL})$, which was purchased from Santa Cruz (USA). Apoptotic cells were determined by the staining of cell nucleus with the DAPI under fluorescence microscope (Olympus, Japan) with a peak excitation wavelength of $340 \mathrm{~nm}$.

\section{Annexin V/PI staining}

NCI-H460, A549 and GLC82 were seeded into 6-well plates and treated with LZ-205 or Wogonin. Cells were then harvested and washed with ice-cold PBS. According to the manufacturer's instructions, cells were stained with Annexin V and Propidium Iodide (PI) in binding buffer for $10 \mathrm{~min}$. Samples were detected and analyzed by flow cytometry (FACSCalibur, BD, USA).

\section{Measurement of ROS formation [35]}

NCI-H460, A549 and GLC82 were plated on 6-well plates, allowed to attach, and exposed to NAC for $1 \mathrm{~h}$. Then cells were treated with LZ-205 for $12 \mathrm{~h}$. Cells were harvested and incubated with $10 \mu \mathrm{M}$ DCFHDA (Beyotime Institute of Biotechnology, China) at $37^{\circ} \mathrm{C}$ for $30 \mathrm{~min}$. After washed by serum-free, the fluorescence intensity was measured by flow cytometry.

\section{Detection of intracellular $\mathrm{Ca}^{2+}$ level}

Cells were treated with LZ-205 for $24 \mathrm{~h}$ and then loaded with $1 \mu \mathrm{M}$ Fluo-3 AM (Beyotime, China) which combined with $\mathrm{Ca}^{2+}$ and produced strong fluorescence. After incubating for $45 \mathrm{~min}$ at $37^{\circ} \mathrm{C}$ in the dark, the cells were resuspended with PBS and the fluorescence intensity were measured by flow cytometry.

\section{Mitochondrial membrane potential ( $\Delta \Psi \mathrm{m})$ assessment}

Briefly, Cells were treated with LZ-205 for $24 \mathrm{~h}$. Then cells were harvested, washed and incubated with JC1((Beyotime Institute of Biotechnology, China). Samples were analyzed by flow cytometry (FACS Calibur, Becton Dickinson) with settings of FL1 (Green, FITC) at $530 \mathrm{~nm}$ and FL2 (Red, PE) at $590 \mathrm{~nm}$, respectively.

\section{Subcellular fractionation [36]}

NCI-H460 cells were treated with LZ-205 for $24 \mathrm{~h}$ and then collected. Mitochondrial and cytosolic fractions proteins were performed using cytosol/mitochondria fractionation kit (KeyGen Biotech, China) according to the following protocol.

\section{Quantitative real-time PCR}

Total RNA isolation and real-time PCR were performed as previously described. The primers in the reaction were used as follows: 
Actin (forward, 5'-GATCTGGCACCACACCT TCT-3'; reverse, 5'-GGGGTGTTGAAGGTCTCAAA-3'); spliced (s) $x b p-1$ (forward, 5'-GAGTCCGCAG CAGGTG-3'; reverse, 5'- GTGTCAGAGTCCATGG GA-3').

\section{Transient transfection with CHOP small interfering RNA (siRNA)}

NCI-H460 cells were grown to $60 \%$ confluence. Then either CHOP-siRNA ( $30 \mathrm{pmol} / \mu \mathrm{L}$ ) or control-siRNA added into the cells with PepMute siRNA Transfection Reagent (SignaGen Laboratories, Rockville, MD). 8 hours later, the cells were harvested for further experiment.

\section{Western blot analysis [37]}

Cells were lysed with a mixture of Pierce RIPA Buffer (Thermo, USA), and a debris was removed by centrifugation at $12,000 \mathrm{Xg}$ for $20 \mathrm{~min}$ at $4^{\circ} \mathrm{C}$. The concentration of total proteins was determined by using the BCA assay method (Thermo, Massachusetts, USA). After added by loading buffer and denaturation, protein samples (with $100 \mu \mathrm{g}$ ) were electrophoresed and transferred to nitrocellulose membranes. Blots were blocked for $2 \mathrm{~h}$ at room temperature, with $5 \%$ nonfat milk (BIO-RAD, USA) in PBS, and then incubated with primary antibodies for $1 \mathrm{~h}$ at $37^{\circ} \mathrm{C}$ and overnight at $4{ }^{\circ} \mathrm{C}$, which was followed by incubation with IRDye 800-labeled secondary antibodies (KPL, Gaithersburg, MD, USA) for $1 \mathrm{~h}$ at room temperature in the dark. Detection was performed by the Odyssey Infrared Imaging System (LI-COR, Lincoln, NE, USA).

\section{Animal model}

Specific pathogen free (SPF) BALB/c nude mice (Shanghai Slac Laboratory Animal Co. Ltd. China) with body weight of 18-22 $\mathrm{g}$ and age of 35-40 days were raised in SPF Animal Laboratory of China Pharmaceutical University. All mice were subcutaneously inoculated with injections of $1 \times 10^{6}$ cells. After 12-14 days, tumor sizes were determined using micrometer calipers, and then nude mice with similar tumor volume (neither too large nor too small) were randomly divided them into 5 groups (with 6 nude mice/group): saline control group, LZ-205 $10,20,40 \mathrm{mg} / \mathrm{kg}$ group and wogonin $60 \mathrm{mg} / \mathrm{kg}$ group. All groups were administered intravenously every two days. Three weeks later, the nude mice were killed, and the tumor xenografts were removed and measured. Tumor volume (TV) was calculated using the following formula: TV $\left(\mathrm{mm}^{3}\right)=\mathrm{D} / 2 \times \mathrm{d}^{2}$, where D and $\mathrm{d}$ are the longest and the shortest diameters, respectively. All the animals were weighed every three days and monitored for mortality throughout the experimental period to assess toxicity of the treatments.

\section{Immunohistochemistry}

The expression of GRP78, CHOP and FasL in tumor tissues of nude mice model was assessed to the method described previously [38], using a Goat-anti-mouse antibody and an Ultra-Sensitive TMSAP kit (Maixin-Bio Co, Fuzhou, China).

\section{Statistical analysis}

All experiments are detected in triplicate $(n=3)$ and expressed as mean \pm SEM. We use the software of SigmaPlot, GraphPad and Excel to analyze these data and Student's $t$-test and two-way ANOVA to analyze the difference between sets of data.

\section{ACKNOWLEDGMENTS}

This work was supported by the National Science \& Technology Major Project (No.2012ZX09304-001), the Project Program of State Key Laboratory of Natural Medicines, China Pharmaceutical University (No. JKGZ201101, SKLNMZZ201210, SKLNMZZCX201303, SKLNMZZJQ201302 and G140042), the Program for Changjiang Scholars and Innovative Research Team in University (IRT1193), the National Natural Science Foundation of China (No. 81473231), the National Science \& Technology Major Project (No. 2013ZX09103001-007), Natural Science Foundation of Jiangsu Province (No. SBK2015010247).

\section{CONFLICTS OF INTEREST}

All the authors declare no competing financial interests.

\section{REFERENCES}

1. Asai N, Ohkuni Y, Kaneko N, Yamaguchi E and Kubo A. Relapsed small cell lung cancer: treatment options and latest developments. Therapeutic advances in medical oncology. 2014; 6:69-82.

2. Nikoletopoulou V, Markaki M, Palikaras $\mathrm{K}$ and Tavernarakis N. Crosstalk between apoptosis, necrosis and autophagy. Biochim Biophys Acta. 2013; 1833:3448-3459.

3. Green DR. Apoptotic pathways: ten minutes to dead. Cell. 2005; 121:671-674.

4. Ola MS, Nawaz M and Ahsan H. Role of Bcl-2 family proteins and caspases in the regulation of apoptosis. Mol Cell Biochem. 2011; 351:41-58.

5. King A, Gottlieb E, Brooks DG, Murphy MP and Dunaief JL. Mitochondria-derived reactive oxygen species mediate blue light-induced death of retinal pigment epithelial cells. Photochem Photobiol. 2004; 79:470-475. 
6. Wang X, Wang B, Fan Z, Shi X, Ke ZJ and Luo J. Thiamine deficiency induces endoplasmic reticulum stress in neurons. Neuroscience. 2007; 144:1045-1056.

7. Sanges D and Marigo V. Cross-talk between two apoptotic pathways activated by endoplasmic reticulum stress: differential contribution of caspase-12 and AIF. Apoptosis. 2006; 11:1629-1641.

8. Sano R and Reed JC. ER stress-induced cell death mechanisms. Biochim Biophys Acta. 2013.

9. Kim I, Xu W and Reed JC. Cell death and endoplasmic reticulum stress: disease relevance and therapeutic opportunities. Nat Rev Drug Discov. 2008; 7:1013-1030.

10. Adams JM. Ways of dying: multiple pathways to apoptosis. Genes Dev. 2003; 17:2481-2495.

11. Huang TT, Liu FG, Wei CF, Lu CC, Chen CC, Lin HC, Ojcius DM and Lai HC. Activation of multiple apoptotic pathways in human nasopharyngeal carcinoma cells by the prenylated isoflavone, osajin. PLoS One. 2011; 6:e18308.

12. Havsteen BH. The biochemistry and medical significance of the flavonoids. Pharmacology \& therapeutics. 2002; 96:67-202.

13. Li-Weber M. New therapeutic aspects of flavones: the anticancer properties of Scutellaria and its main active constituents Wogonin, Baicalein and Baicalin. Cancer Treat Rev. 2009; 35:57-68.

14. Banerjee A, Ahmed H, Yang P, Czinn SJ and Blanchard TG. Endoplasmic reticulum stress and IRE-1 signaling cause apoptosis in colon cancer cells in response to andrographolide treatment. Oncotarget. 2016; 7:4143241444. doi: 10.18632/oncotarget.9180.

15. Chen YC, Shen SC, Lee WR, Lin HY, Ko CH, Shih CM and Yang LL. Wogonin and fisetin induction of apoptosis through activation of caspase 3 cascade and alternative expression of $\mathrm{p} 21$ protein in hepatocellular carcinoma cells SK-HEP-1. Arch Toxicol. 2002; 76:351-359.

16. Wang W, Guo Q, You Q, Zhang K, Yang Y, Yu J, Liu W, Zhao $\mathrm{L}, \mathrm{Gu} \mathrm{H}, \mathrm{Hu} \mathrm{Y}$, Tan Z and Wang X. Involvement of bax/bcl-2 in wogonin-induced apoptosis of human hepatoma cell line SMMC-7721. Anticancer Drugs. 2006; 17:797-805.

17. Wei L, Lu N, Dai Q, Rong J, Chen Y, Li Z, You Q and Guo Q. Different apoptotic effects of wogonin via induction of $\mathrm{H}(2) \mathrm{O}(2)$ generation and $\mathrm{Ca}(2+)$ overload in malignant hepatoma and normal hepatic cells. J Cell Biochem. 2010; 111:1629-1641.

18. Lin CC, Kuo CL, Lee MH, Lai KC, Lin JP, Yang JS, Yu CS, Lu CC, Chiang JH, Chueh FS and Chung JG. Wogonin triggers apoptosis in human osteosarcoma U-2 OS cells through the endoplasmic reticulum stress, mitochondrial dysfunction and caspase-3-dependent signaling pathways. Int J Oncol. 2011; 39:217-224.

19. Huang KF, Zhang GD, Huang YQ and Diao Y. Wogonin induces apoptosis and down-regulates survivin in human breast cancer MCF-7 cells by modulating PI3K-AKT pathway. Int Immunopharmacol. 2012; 12:334-341.
20. Chen FH, Zhang LB, Qiang L, Yang Z, Wu T, Zou MJ, Tao L, You QD, Li ZY, Yang Y and Guo QL. Reactive oxygen species-mitochondria pathway involved in LYG202-induced apoptosis in human hepatocellular carcinoma HepG(2) cells. Cancer Lett. 2010; 296:96-105.

21. Pan D, Li W, Miao H, Yao J, Li Z, Wei L, Zhao L and Guo Q. LW-214, a newly synthesized flavonoid, induces intrinsic apoptosis pathway by down-regulating Trx-1 in MCF-7 human breast cells. Biochem Pharmacol. 2014; 87:598-610.

22. Park GB, Kim YS, Lee HK, Song H, Kim S, Cho DH and Hur DY. Reactive oxygen species and p38 MAPK regulate Bax translocation and calcium redistribution in salubrinalinduced apoptosis of EBV-transformed B cells. Cancer Lett. 2011; 313:235-248.

23. Yu JQ, Liu HB, Tian DZ, Liu YW, Lei JC and Zou GL. Changes in mitochondrial membrane potential and reactive oxygen species during wogonin-induced cell death in human hepatoma cells. Hepatol Res. 2007; 37:68-76.

24. Moreira PI, Honda K, Liu Q, Santos MS, Oliveira CR, Aliev G, Nunomura A, Zhu X, Smith MA and Perry G. Oxidative stress: the old enemy in Alzheimer's disease pathophysiology. Curr Alzheimer Res. 2005; 2:403-408.

25. Smaili SS, Pereira GJ, Costa MM, Rocha KK, Rodrigues L, do Carmo LG, Hirata H and Hsu YT. The role of calcium stores in apoptosis and autophagy. Curr Mol Med. 2013; 13:252-265.

26. Oyadomari S and Mori M. Roles of CHOP/GADD153 in endoplasmic reticulum stress. Cell Death Differ. 2004; 11:381-389.

27. McCullough KD, Martindale JL, Klotz LO, Aw TY and Holbrook NJ. Gadd153 sensitizes cells to endoplasmic reticulum stress by down-regulating $\mathrm{Bcl} 2$ and perturbing the cellular redox state. Mol Cell Biol. 2001; 21:1249-1259.

28. Jiang $X$ and Wang $X$. Cytochrome $\mathrm{C}$-mediated apoptosis. Annual review of biochemistry. 2004; 73:87-106.

29. Norberg E, Orrenius S and Zhivotovsky B. Mitochondrial regulation of cell death: processing of apoptosis-inducing factor (AIF). Biochem Biophys Res Commun. 2010; 396:95-100.

30. Del Poeta G, Venditti A, Del Principe MI, Maurillo L, Buccisano F, Tamburini A, Cox MC, Franchi A, Bruno A, Mazzone C, Panetta P, Suppo G, Masi M and Amadori S. Amount of spontaneous apoptosis detected by $\mathrm{Bax} / \mathrm{Bcl}-2$ ratio predicts outcome in acute myeloid leukemia (AML). Blood. 2003; 101:2125-2131.

31. Baumann S, Fas SC, Giaisi M, Muller WW, Merling A, Gulow K, Edler L, Krammer PH and Li-Weber M. Wogonin preferentially kills malignant lymphocytes and suppresses T-cell tumor growth by inducing PLCgamma1- and Ca2+dependent apoptosis. Blood. 2008; 111:2354-2363.

32. Sola S, Morgado AL and Rodrigues CM. Death receptors and mitochondria: two prime triggers of neural apoptosis and differentiation. Biochim Biophys Acta. 2013; 1830:2160-2166. 
33. Roy S and Nicholson DW. Cross-talk in cell death signaling. J Exp Med. 2000; 192:F21-25.

34. Zhang Y, Zhao L, Li X, Wang Y, Yao J, Wang H, Li F, Li $\mathrm{Z}$ and Guo Q. V8, a newly synthetic flavonoid, induces apoptosis through ROS-mediated ER stress pathway in hepatocellular carcinoma. Arch Toxicol. 2014; 88:97-107.

35. Zou P, Chen M, Ji J, Chen W, Chen X, Ying S, Zhang J, Zhang Z, Liu Z, Yang S and Liang G. Auranofin induces apoptosis by ROS-mediated ER stress and mitochondrial dysfunction and displayed synergistic lethality with piperlongumine in gastric cancer. Oncotarget. 2015; 6:3650536521. doi: 10.18632/oncotarget.5364.

36. Qiao C, Lu N, Zhou Y, Ni T, Dai Y, Li Z, Guo Q and Wei L. Oroxylin A modulates mitochondrial function and apoptosis in human colon cancer cells by inducing mitochondrial translocation of wild-type p53. Oncotarget. 2016; 7:1700917020. doi: 10.18632/oncotarget.7927.

37. Zhang YH, Wang Y, Yusufali AH, Ashby F, Zhang D, Yin ZF, Aslanidi GV, Srivastava A, Ling CQ and Ling C. Cytotoxic genes from traditional Chinese medicine inhibit tumor growth both in vitro and in vivo. Journal of integrative medicine. 2014; 12:483-494.

38. Wang H, Zhao L, Zhu LT, Wang Y, Pan D, Yao J, You QD and Guo QL. Wogonin reverses hypoxia resistance of human colon cancer HCT116 cells via downregulation of HIF-1alpha and glycolysis, by inhibiting PI3K/Akt signaling pathway. Mol Carcinog. 2014; 53:E107-118. 